\title{
ANALISA KADAR LOGAM BERAT (Pb) PADA KUKU TUKANG TAMBAL BAN DISEPANJANG JALAN KAPTEN MUSLIM SECARA SPEKTROFOTOMETER SERAPAN ATOM
}

\author{
Dyna Grace Romatua Aruan ${ }^{1}$, Sulistina manurung ${ }^{2}$. \\ ${ }^{12}$ Prodi Analis dan Teknologi Laboratorium Medik, Fakultas Pendidikan Vokasi Universitas Sari \\ Mutiara Indonesia \\ Email: dynaaruan1245@gmail.com, sulistina064@gmail.com
}

\begin{abstract}
ABSTRAK
Timbal $(\mathrm{Pb})$ merupakan salah satu jenis logam berat berbahaya dan toksik bagi tubuh manusia. Tambal ban merupakan profesi yang bersangkutan dengan ban, dimana kemungkinan terpapar partikel timbal akibat polusi atau emisi gas kendaraan bermotor dengan kadar jauh lebih tinggi dibanding dengan masyarakat lainnya sangat nyata. Kuku termasuk salah satu anatomi tubuh yang digunakan sebagai alat ukur untuk mengetahui tingkat kadar timbal dalam tubuh manusia. Menurut WHO ( World Health Organization) tahun 1995 tingkat kadar timbal dalam tubuh manusia dibagi menjadi 3 (Tiga) tingkat yaitu, rendah (<10 ppm), sedang ( 10-25 ppm) ataupun tinggi (>25 ppm) sesuai kategori pencemaran WHO tahun 1995. Penelitian ini bertujuan untuk mengetahui tingkat kadar timbal pada Tukang tambal ban yang diambil di sepanjang Jalan Kapten Muslim dengan mengambil sampel kukunya. Penelitian ini dilaksankan di UPT Laboratorium Kesehatan Daerah Provinsi Sumatera Utara dengan menggunakan alat Spektrofotometer Serapan Atom. Dari 6 keseluruhan populasi, penelitian mengambil sampel kuku dari 6 (enam) orang tambal ban. Hasil penelitian yang diperoleh menunjukkan bahwa dari 6 (enam) sampel kuku, 1 diantaranya dinyatakan dengan lama kerja >10 thn dengan kadar13,70 mg/ kg termasuk dengan Standar Baku Mutu WHO Tahun 1995 yaitu termasuk tingkat pencemaran sedang.sedangkan sampel dengan lama kerja 5-10 thn, 3-5 thn dan <3 thn termasuk tingkat pencemaran (>10 ppm)/(mg/kg). Dan disarankan kepada peneliti selanjutnya agar melakukan penelitian dengan mengambil sampel lain seperti rambut atau darah untuk mendapat hasil yang lebih akurat.
\end{abstract}

Kata kunci ;Kuku, Timbal (Pb), Tambal Ban, Spektrofotometer Serapan Atom.

\section{ABSTRACT}

Lead $(\mathrm{Pb})$ is a type of heavy metal that is dangerous and toxic to the human body. Tire patching is a profession related to tires, where the possibility of being exposed to lead particles due to pollution or motor vehicle gas emissions with levels much higher than other communities is very real. Nails are one of the anatomy of the body that is used as a measuring tool to determine the level of lead levels in the human body. According to WHO (World Health Organization) in 1995 the level of lead levels in the human body was divided into 3 (three) levels, namely, low (<10 ppm), medium (10-25 ppm) or high (>25 ppm) according to the WHO pollution category in 2005. 1995. The aim of this study was to determine the level of lead in tire repairers taken along Jalan Captain Muslim by taking a sample of his nails. This research was carried out at the UPT Regional Health Laboratory of North Sumatra Province using an Atomic Absorption Spectrophotometer. From 6 total populations, the study took nail samples from 6 (six) people with tire patches. The results obtained showed that from 6 (six) nail samples, 1 of them was stated to have a length of work > 10 years with a level of $13.70 \mathrm{mg} / \mathrm{kg}$ including the 1995 WHO Quality Standards, which included a moderate level of pollution. -10 yr, 3-5 $y r$ and $<3 y r$ including pollution level $(>10 \mathrm{ppm}) /(\mathrm{mg} / \mathrm{kg})$. And it is suggested to further researchers to conduct research by taking other samples such as hair or blood to get more accurate results 


\section{PENDAHULUAN}

Kesibukan yang terjadi di jalan raya dipastikan memberi kontribusi yang besar terhadap pencemaran udara daerah tersebut. Meningkatkan penggunaan kendaraan bermotor akan menurunkan kecepatan rata-rata kendaraan di jalan raya. Penurunan kecepatan rata-rata kendaraan akan akan menurun kualitas emisi gas buang kendaraan. Kecepatan rata-rata kendaraan yang berkaitan dengan pola berkendara ini akan sangat mempengaruhi jumlah pelepasan senyawa tersebut ke atmosfer.(Kusumawati etal, 2013).

Salah satu aspek lingkungan yang dapat mengalami penurunan kualitas adalah udara karena emisi gas buang dari kendaraan bermotor meningkat. Dari total pencemaran udara yang ada, asap kendaraan berbahan bakar merupakan penyumbang tertinggi yaitu $66,34 \%$. Didalam asap kendaraan bermotor, ada salah satu unsur yang berbahaya yaitu timbal/Plumbum $(\mathrm{Pb})$ (Izainie, 2010)

Udara bersih adalah udara yang cukup akan kebutuhan oksigen (O2) yang dibutuhkan makhluk hidup untuk proses fisiologis normal. Didaerah perkotaan yang ramai, gas pencemar berasal dari asap kendaraan, gas buangan pabrik, pembangkit tenaga listrik, asap rokok dan sebagainya yang erat hubungannya dengan aktivitas kehidupan manusia (Darmono, 2009).

Terabsorpsinya senyawa timbal kedalam tubuh dapat melalui jalur inhalasi, ingesti, dan kontak dengan permukaan kulit. Timbal akan ikut dalam sikulasi darah ke seluruh tubuh dan didistribusikan kedalam jaringan lunak dan jaringan keras. Ekskresi timbal umunya berjalan sangat lambat sehingga kandungan timbal dalam tubuh dapat terus menerus. Palar (2008)

Pencemaran $\mathrm{Pb}$ dalam lingkungan hidup kita sehari-hari menyebabkan terjadinya bahaya toksik pada manusia, perubahan biofser atau perubahan lingkungan luar. Salah satunya adanya emisi gas bungan dari gas kendaraan bermotor yang mengandung $\mathrm{Pb}$ (Plumbum). Emisi gas buangan merupakan hasil samping dari pembakaran yang terjadi dalam mesinmesin kendaraan. $\mathrm{Pb}$ merupakan hasil samping dari pembakaran tersebut berasal dari senyawa tetrametil- $\mathrm{Pb}$ dan terraetil- $\mathrm{Pb}$ yang selalu ditambhkan dalam bahan bakar kendaraan bermotor pada mesin-mesin kendaraan (Palar,1994)

Timbal atau dalam keseharian lebih dikenal dengan nama timah hitam, dalam bahasa ilmiah disebut Plumbum dan disimbol dengan $\mathrm{Pb}$. Timbal dalam susunan berkala mempunyai berat atom $207,2 \mathrm{gr} / \mathrm{mol}$. Logam berat bewarna kelabu kebiruan ini mudah menguap dengan titik lebur 327,5 oC dan titik didihh $1620 \mathrm{oC}$. Pada suhu antara $550 \mathrm{oC}-600 \mathrm{oC}$ timbal menguap dan bereaksii dengan oksigen dalam udara membentuk timbal oksida, $\mathrm{Pb}$ atau timbal dalam kehidupan merupakan senyawa kimia yang digunakan sebagai campuran bensin. (Widowati,2008).

Sebagai polutan, $\mathrm{Pb}$ memilki dampak buruk pada lingkungan dan juga makhluk hidup. Pada lingkungan, $\mathrm{Pb}$ dapat mencemari udara, air dan tanah, sedangkan pada makhluk hidup $\mathrm{Pb}$ dapat masuk kedalam tubuh dan mengendap di dalam darah. $\mathrm{Pb}$ dapat mengakibatkan efek toksik pada paparan yang sangat rendah sekalipun. Efek secara akut atapun kronis terhadap kesehatan manusia meliputi gangguan pada sistem organ didalam tubuh. Efek buruk ini tidak hanya menyerang manusia dewasa saja, anak-anak dan janin yang masih didalam kandungan sekalipun dapat merasakan efek toksik dari timbal.

$\mathrm{Pb}$ dan senyawanya masuk kedalam 
Dyna Grace Romatua Aruan et. all |Analisa Kadar Logam Berat (PB) Pada Kuku Tukang Tambal Ban Disepanjang Jalan Kapten Muslim Secara Spektrofotometer Serapan Atom

tubuh manusia terutama melalui saluran pernafasan dan pencernaan, sedangkan absorbsinya melalui kulit sangat kecil sehingga dapat di abaikan. $\mathrm{Pb}$ yang di absorbsi diangkut oleh darah ke organorgan tubuh, dimana $95 \% \mathrm{~Pb}$ dalam darah diikat oleh eritrosit. Unsur $\mathrm{Pb}$ di dalam tubuh dapat terdeposit pada jaringan lunak (sumsum tulang, sistem syaraf, ginjal, dan hati) serta jaringan keras ( tulang, gigi, kuku, dan rambut), dimana unsur $\mathrm{Pb}$ pada jaringan lunak bersifat toksik pada jaringan itu sendiri (Adryanto,2005).

Mekanik tambal ban merupakan salah satu profesi di bidang kendaraan bermotor, dimana kemungkinan terpapar partikel $\mathrm{Pb}$ akibat polusi karena letaknya yang selalu dipinggir jalan atau emisi gas kendaraan bermotor dengan kadar jauh lebih tinggi dibandingkan dengan masyarakat lainnya sangat nyata. Oleh karena itu, paparan $\mathrm{Pb}$ akan lebih tepat, apalagi bila disertai dengan durasi paparan yang panjang. Menurut penelitian sebelumnya yang dilakukan oleh Wahyu (2015) mengatakan bahwa kadar timbal pada kuku Polantas di Kota Bengkalis sebesar 2,56 ppm dan termasuk dalam kategori pencemaran rendah menurut WHO tahun 1995.

Menurut Penelitian, Wahyu Hardiansyah (2005) tentang kadar $\mathrm{Pb}$ pada rambut dan kuku polisi lalu lintas di Pekanbaru dan Bengkalis bahwa dikategorikan dengan merujuk pada batasan kadar timbal dalam darah yang dikeluarkan oleh WHO Tahun 1995 Tentang Tingkat Kadar Timbal di Tubuh Manusia,dapat diketahui bahwa kadar timbal pada rambut Polantas di Kota Pekanbaru dengan masa kerja $<3$ tahun, 3-5 tahun dan > 10 tahun sebesar 13,36 ppm dan termasuk dalam kategori pencemaran sedang menurut WHO Tahun 1995

Tentang Tingkat Kadar Timbal di
Tubuh Manusia. Sedangkan kadar timbal pada kuku Polantas di Kota Pekanbaru sebesar 2,11 ppm dan termasuk dalam kategori pencemaran rendah.

Menurut Penelitian Sukma Wiratma (2018) tentang studi bioakumulasi ion logam $\mathrm{Pb}$ dalam rambut dan darah operator stasiun pengisian bahan bakar umum, jalan sentosa, Samarinda pada sampel dengan rentang bekerja yang sama yaitu 1tahun, 3tahun, 4tahun, 5tahun, 6tahun, 7tahun, 9tahun, 10tahun. Terjadinya perbedaan dan kesamaan nilai konsentrasi di antara beberapa sampel di atas tidak hanya dipengaruhi oleh rentang masa bekerja saja namun pola hidup, keadaan lingkungan dan kebiasaan memakai alat pelindung diri (APD). Semakin lama bekerja pada tempat yang terpapar $\mathrm{Pb}$ maka potensi terakumulasi kadar ion logam $\mathrm{Pb}$ dalam rambut, darah dan bagian lain juga semakin besar.

Menurut penelitian Endatari Lia (2019), tentang logam berat timbal $(\mathrm{Pb})$ pada sampel rambut operator SPBU di Tanjung Morawa menunjukkan tidak ada kadar yang melebihi ambang batas yang telah di tentukan, dimana batasan normal timbal pada rambut yaitu $<10 \mathrm{ppm}$.

Berdasarkan penelitian diatas, oleh karena itu, penulis ingin melakukan penelitian tentang "Analisa kadar Logam Berat $(\mathrm{Pb})$ Pada kuku Tukang Tambal Ban di Sepanjang Jalan Kapten Muslim Secara Spektrofotometri Serapan Atom." Dengan kriteria lama kerja $<3$ thn, 3-5 thn, 5-10 dan >10 thnPendahuluan mencakup latar belakang atas suatu permasalahan serta urgensi dan rasionalisasi kegiatan (penelitian atau pengabdian). Tujuan kegiatan dan rencana pemecahan masalah disajikan dalam bagian ini. Tinjauan pustaka yang relevan dan pengembangan hipotesis dimasukkan dalam bagian ini. 


\section{METODE PENELITIAN}

Jenis penelitian ini dilakukan secara deskriptif dengan pendekatan cross sectional yaitu data dikumpulkan hanya pada suatu waktu tertentu dan bertujuan untuk mengetahui kadar logam berat timbal $(\mathrm{Pb})$ pada kuku tukang tambal ban di sepanjang jalan Kapten Muslim Secara Spektofotometer Serapan Atom.

Penelitian ini direncanakan di tempat tukang tambal ban yang ada di sepanjang jalan Kapten Muslim kemudian dilanjutkan dengan analisa laboratorium di UPT balai laboratorium kesehatan daerah provinsi sumatera utara jalan Williem Iskandar Pasar V Barat 1 No, 4 Medan.

Populasi dalam penelitian ini adalah seluruh kuku tukang tambal Ban yang bekerja di sepanjang jalan Kapten Muslim, dimana jumlah populasi sebanyak 6 (Enam) orang.

Peralatan yang Digunakan

\begin{tabular}{|c|c|c|c|}
\hline No & Nama alat & Ukuran & Merek \\
\hline 1 & Beaker glass & $50 \mathrm{ml}$ & Pyrex \\
\hline 2 & Labu ukur & $50 \mathrm{ml}$ & Pyrex \\
\hline 3 & Batang pengaduk & - & - \\
\hline 4 & Erlenmeyer & $50 \mathrm{ml}$ & Pyrex \\
\hline 5 & Pipet volume & $10 \mathrm{ml}$ & Pyrex \\
\hline 6 & Kaca arloji & - & - \\
\hline 7 & Waterbath & - & Memmert \\
\hline 8 & Neraca analitik & - & Maspion \\
\hline 9 & Hot plate & - & Memmert \\
\hline 10 & Oven & - & - \\
\hline 11 & Bola aspirator & - & Varian \\
\hline 12 & Kantong Polisilen & - & - \\
\hline 13 & Spektrofotometer & - & \\
\hline
\end{tabular}

Bahan yang digunakan

\begin{tabular}{|l|c|c|}
\hline No & Nama Reagenisa & Rumus kimia Reagenesia \\
\hline 1 & Asam Nitrat Pekat $65 \%$ & $\mathrm{HNO}_{3}(\mathrm{P})$ \\
\hline 2 & Kalium Kronat $1 \%$ & $\mathrm{~K}_{2} \mathrm{CrO}_{4}$ \\
\hline 3 & Kalium Iodida $1 \%$ & $\mathrm{KI}$ \\
\hline 4 & Asam Klorida & $\mathrm{HCI}(\mathrm{P})$ \\
\hline 5 & Aseton & $\mathrm{C}_{3} \mathrm{H}_{6} \mathrm{O}(\mathrm{P})$ \\
\hline 6 & Detergen & $\mathrm{NaC}_{12} \mathrm{H}_{25} \mathrm{SO}_{4}$ \\
\hline 7 & Aquadest & $\mathrm{H}_{2} \mathrm{O}$ \\
\hline
\end{tabular}

3. Dipanaskan hingga mendidih \pm 30 menit di atas hot plate, hingga seluruh kuku melarut. timbanglah kuku dengan neraca analitik tersebut sebanyak 0.5 gram secara akurat ke dalam beaker glass.

2. Kemudian ditambahkan $\pm 15 \mathrm{ml} \mathrm{HCI}$ dan $5 \mathrm{ml} \mathrm{HNO} 3$ dan ditutup dengan kaca arloji yang sesuai.
4. Kemudian penutup kaca arloji dibuka dan larutan diuapkan di atas waterbath.

5. Kemudian tambahkan lagi $12.5 \mathrm{ml}$ HNO3.

6. Lalu larutan dipanaskan hingga larut 
Dyna Grace Romatua Aruan et. all |Analisa Kadar Logam Berat (PB) Pada Kuku Tukang Tambal Ban Disepanjang Jalan Kapten Muslim Secara Spektrofotometer Serapan Atom

semua dan kembali didinginkan di atas waterbath.

7. Larutan dipindahkan ke dalam labu ukur $50 \mathrm{ml}$ sambil dibilas dengan aquadest dan ditepatkan hingga tanda batas.

\section{HASIL DAN PEMBAHASAN}

Dari hasil penelitian yang dilakukan pada 6 ( enam) sampel kuku mekanik yang diperiksa di UPT Laboratorium Kesehatan Daerah Provinsi Sumatera Utara pada 14-15 Juni 2021 diperoleh hasil sebagai berikut:

Data Hasil Uji Kualitatif Pemeriksaan Kadar Pb pada Kuku Tukang Tambal Ban

\begin{tabular}{|c|c|c|c|c|c|}
\hline \multirow[t]{2}{*}{ No } & \multirow{2}{*}{$\begin{array}{l}\text { Kode } \\
\text { Sampel }\end{array}$} & \multicolumn{3}{|c|}{ Preaksi } & \multirow[t]{2}{*}{ Keterangan } \\
\hline & & $\mathrm{KI}$ & $\mathrm{HCl}$ & $\mathrm{K}_{2} \mathrm{C}_{\mathrm{r}} \mathrm{O}_{4}$ & \\
\hline \multirow{3}{*}{1.} & & $(+)$ & $(+)$ & $(+)$ & Positif \\
\hline & Standar & Kuning & Endapan & Kuning & Mengandung $\mathrm{Pb}$ \\
\hline & {$\left[\mathrm{Pb}\left(\mathrm{NO}_{3}\right)_{2}\right]$} & $\begin{array}{l}\text { Kenari } \\
(+)\end{array}$ & $\begin{array}{l}\text { Putih } \\
(+)\end{array}$ & $\begin{array}{l}\text { Pucat } \\
(+)\end{array}$ & Positif \\
\hline \multirow[t]{2}{*}{2.} & KI & Kuning & Endapan & Kuning & Mengandung $\mathrm{Pb}$ \\
\hline & $>10$ thn & $\begin{array}{l}\text { Kenari } \\
(-)\end{array}$ & $\begin{array}{l}\text { Putih } \\
(-)\end{array}$ & $\begin{array}{l}\text { Pucat } \\
(-)\end{array}$ & Negatif \\
\hline \multirow[t]{2}{*}{3.} & $\mathrm{~K} 2$ & Kuning & Endapan & Kuning & Mengandung $\mathrm{Pb}$ \\
\hline & $5-10$ thn & $\begin{array}{l}\text { Kenari } \\
(-)\end{array}$ & $\begin{array}{l}\text { Putih } \\
(-)\end{array}$ & $\begin{array}{l}\text { Pucat } \\
(-)\end{array}$ & Negatif \\
\hline \multirow[t]{2}{*}{4.} & $\mathrm{~K} 3$ & Kuning & Endapan & Kuning & Mengandung $\mathrm{Pb}$ \\
\hline & $5-10$ thn & $\begin{array}{l}\text { Kenari } \\
(-)\end{array}$ & $\begin{array}{l}\text { Putih } \\
(-)\end{array}$ & $\begin{array}{l}\text { Pucat } \\
(-)\end{array}$ & Negatif \\
\hline \multirow[t]{2}{*}{5.} & $\mathrm{~K} 4$ & Kuning & Endapan & Kuning & Mengandung $\mathrm{Pb}$ \\
\hline & $3-5$ thn & $\begin{array}{l}\text { Kenari } \\
(-)\end{array}$ & $\begin{array}{l}\text { Putih } \\
(-)\end{array}$ & $\begin{array}{l}\text { Pucat } \\
(-)\end{array}$ & Negatif \\
\hline \multirow[t]{2}{*}{6.} & K5 & Kuning & Endapan & Kuning & Mengandung $\mathrm{Pb}$ \\
\hline & $3-5$ thn & $\begin{array}{l}\text { Kenari } \\
(-)\end{array}$ & $\begin{array}{l}\text { Putih } \\
(-)\end{array}$ & $\begin{array}{l}\text { Pucat } \\
(-)\end{array}$ & Negatif \\
\hline \multirow[t]{2}{*}{7.} & K6 & Kuning & Endapan & Kuning & Mengandung $\mathrm{Pb}$ \\
\hline & $<3$ thn & Kenari & Putih & Pucat & \\
\hline
\end{tabular}

Tabel

Data Hasil Uji Kuantitatif Pemeriksaan Kadar Pb pada Kuku Tambal ban dengan Spektrofotometer Serapan Atom

\begin{tabular}{|c|c|c|c|c|}
\hline No & Nama & Satuan & $\begin{array}{c}\text { Hasil Analisa } \\
\text { Timbal }(\mathbf{P b})\end{array}$ & $\begin{array}{c}\text { Tingkat pencemaran Pb ( WHO } \\
\text { tahun 1995) }\end{array}$ \\
\hline 1 & Ronal & $\mathrm{mg} / \mathrm{kg}$ & 13.70 & Pencemaran Sedang $(10-25 \mathrm{ppm})$ \\
\hline 2 & Manik & $\mathrm{mg} / \mathrm{kg}$ & 0.218 & Pencemaran Rendah $(<10 \mathrm{ppm})$ \\
\hline 3 & Bayen & $\mathrm{mg} / \mathrm{kg}$ & 1.342 & Pencemaran Rendah $(<10 \mathrm{ppm})$ \\
\hline 4 & Marbun & $\mathrm{mg} / \mathrm{kg}$ & 3.955 & Pencemaran Rendah $(<10 \mathrm{ppm})$ \\
\hline 5 & Thamrin & $\mathrm{mg} / \mathrm{kg}$ & 1.985 & Pencemaran Rendah $(<10 \mathrm{ppm})$ \\
\hline 6 & Ibnu & $\mathrm{mg} / \mathrm{kg}$ & 2.080 & Pencemaran Rendah $(<10 \mathrm{ppm})$ \\
\hline
\end{tabular}


Dyna Grace Romatua Aruan et. all |Analisa Kadar Logam Berat (PB) Pada Kuku Tukang Tambal Ban Disepanjang Jalan Kapten Muslim Secara Spektrofotometer Serapan Atom

\section{Pembahasan}

Dari tabel 4.2 data hasil penelitian diperoleh hasil yang menunjukkan bahwa kadar $\mathrm{Pb}$ pada 6 (enam) sampel kuku tukang tambal ban di sepanjang Jalan Kapten Muslim dengan variabel lama kerja $>10$ th (K1) Ronal $13.70 \mathrm{mg} / \mathrm{kg}$ termasuk katagori pencemaran yang sedang yaitu 10-25 ppm, sedangkan sampel dengan lama kerja 5-10 th (K2) Marbun 3.955 $\mathrm{mg} / \mathrm{kg}, 5-10$ thn (K3) Ibnu $2.080 \mathrm{mg} / \mathrm{kg}$, 3-5 thn (K4) Thamrin $1.985 \mathrm{mg} / \mathrm{kg}, 3-5$ thn (K5) Bayen $1.342 \mathrm{mg} / \mathrm{kg}$ dan $<3$ thn (K6) Manik $0.218 \mathrm{mg} / \mathrm{kg}$ dinyatakan mengandung timbal dengan kategori pencemaran yang rendah dengan kadar < 10 ppm. Beberapa faktor yang menyebabkan hasil kadar $\mathrm{Pb}$ pada penelitian termasuk kategori pencemaran rendah 10-25 ppm diantaranya adalah yaitu tingkat lama pekerjaan, faktor usia dan pola hidup . Sedangkan hasil kadar $\mathrm{Pb}$ pada penelitian ini dinyatakan termasuk pencemaran rendah $<10$ ppm dikarenakan tukang tambal ban tersebut menjaga kebersihan pada kukunya, seperti rajin memotong kuku dan menjaga kebersihan lingkungan kerja. Selain itu, tekstur kuku mekanik dalam penelitian ini menunjukkan ciri yaitu beberapa kuku yang terlihat

\section{SIMPULAN}

Dari hasil penelitian yang dilakukan di UPT Laboratorium Kesehatan Daerah Provinsi Sumatera Utara menunjukkan hasil bahwa kadar $\mathrm{Pb}$ (Timbal) pada kuku tukang tambal ban disepanjang jalan Kapten Muslim diuraikan sebagai berikut : Dari 6 (enam) sampel kuku, 1 diantaranya dinyatakan dengan variabel lama kerja $>10$ thn dengan kadar 13.70 $\mathrm{mg} / \mathrm{kg}$ termasuk dengan Standar Baku Mutu WHO Tahun 1995 yaitu termasuk tingkat pencemaran sedang yaitu 10-25 ppm.sedangkan sampel dengan lama kerja 5-10 thn, 3-5 thn dan <3 thn termasuk tingkat pencemaran rendah $(>10$ $\mathrm{ppm}) /(\mathrm{mg} / \mathrm{kg})$. bewarna putih dan sebagiannya bewarna hitam, teksturnya tidak keras dan kering, dan berukuran pendek.

Dan sampel yang dinyatakan termasuk kategori pencemaran dengan kadar 10- 25 ppm yaitu sampel yang memiliki masa kerja yang paling lama yaitu $>10$ thn dengan kadar $13.70 \mathrm{mg} / \mathrm{kg}$ termasuk dengan Standar Baku Mutu WHO Tahun 1995 yaitu sedang.

Hasil penelitian ini menunjukkan bahwa kadar timbal pada tubuh manusia yang diwakili oleh kuku cenderung mengalami peningkatan seiring dengan durasi paparan timbal di udara yang diwakili oleh lamanya masa kerja, dimana tampak adanya kecenderungan bahwa semakin lama bekerja maka kadar timbal dalam tubuh akan semakin tinggi pula. lamanya paparan polutan lingkungan terhadap tubuh manusia tidak berkaitan langsung dengan tingkat polusi pada udara ambien. Hal ini dikarenakan banyak faktor yang mempengaruhi hubungan antara kadar udara ambien dengan paparan terhadap manusia, seperti toksikokinetik, jalur kontak paparan polutan terhadap tubuh manusia melalui perantara yang berbeda beserta absorpsinya, dan sebagiannya

\section{UCAPAN TERIMA KASIH}

Pada kesempatan ini penulis mengucapkan Terimakasih yang sebesarbesarnya kedua orangtua, Abang dan adek tercinta yang selalu memberi semangat dalam terlaksanakan penelitian ini, kepada teman-teman dan pihak yang telah membantu dalam melaksanakan penelitian ini.Berisi ucapan terima kasih kepada lembaga pemberi dana/individu, dan atau yang telah membantu dalam pelaksanaan penelitian dan penulisan manuskrip serta lembaga afiliasi penulis. 
Dyna Grace Romatua Aruan et. all |Analisa Kadar Logam Berat (PB) Pada Kuku Tukang Tambal Ban Disepanjang Jalan Kapten Muslim Secara Spektrofotometer Serapan Atom

DAFTAR PUSTAKA

Adryanto. 2005.Deteksi Pencemaran

Timah Hitam (Pb) dalam Darah, Masyarakay yang Terpajan Timbal (Plumbum), Jurnal Kesehatan Lingkungan Vol-2/No.1

Darmono. 2009. Farmasi Forensik dan

Toksikologi.Jakarta : UI Press.

Hardiansyah Putra, Wahyu,dkk. Kadar

Timbal $(\mathrm{Pb})$ pada Rambut dan Kuku

Polisi Lalu Lintas Di Kota Bengkalis. Jurnal Dinamika Lingkungan Indonesia, Juli 2015,p 121-128. Vol-2/No.2

Irianto, K. 2013. Pencegahan dan Penanggulangan Keracunan Bahan Kimia Berbahaya. Jakarta : Yrama Widya.

Palar, H. 1994. Pencemaran dan Toksikologi Logam Berat. Jakarta : Rineka Cipta

Palar, H. 2012. Pencemaran dan Toksikologi Logam Berat. Jakarta :

Rineka Cipta

Panker, Steve.2007. Ensiklopedia

Tubuh Manusia.jakarta : Erlangga

Raylene, M Rospond. 2008. Kulit,

Rambut, Kuku. Terjemahan Benediktus

Yohana, D. Lyrawati, 2009.

Siswanto, A 1991. Toksikologi Industri.

Surabaya : Balai Hiperkes dan

Keselamatan Depnaker jatim.

Skoog, Hooler Nieman. 1998. Principles od Instrumental Analysis, $5^{\text {th }}$ ed.

Sanders Collige publishing, USA.

Sumardjo, D. 2009. Pengantar Kimia.

Jakarta :EGC

Widowati. 2008. Efek Toksik dan
Penanggulangan Pencemaran.

Yogyakarta : Andi

Anonim. 2012. Penyakit Akibat Kerja Karena Pajanan Logam Berat. Jakarta : Kemenkes 
Dyna Grace Romatua Aruan et. all |Analisa Kadar Logam Berat (PB) Pada Kuku Tukang

Tambal Ban Disepanjang Jalan Kapten Muslim Secara Spektrofotometer Serapan Atom 